EESTI NSV TEADUSTE AKADEEMIA TOIMETISED. VIII KÖIDE BIOLOOGILINE SEERIA. 1959, NR. 3

ИЗВЕСТИЯ АКАДЕМИИ НАУК ЭСТОНСКОИ ССР. ТОМ VIII СЕРИЯ БИОЛОГИЧЕСКАЯ. $1959, ﹎{2} 3$

\title{
LEHISEKULTUURIDEST JA NENDE TERVISLIKUST SEISUNDIST EESTI NSV-s
}

\author{
M. MARGUS, \\ põllumajandusteaduste kandidaat
}

Metsade tootlikkuse tõstmiseks on olemas järgmised tähtsamad viisid: valida kasvukohale vastavad sobivad puuliigid ja nende otstarbekad segamisviisid; reguleerida õigeaegselt puude- ja puuliikidevahelisi suhteid; parandada metsakasvutingimusi. Puuliikide valikul eelistatakse väärtuslikke kiirekasvulisi kohalikke liike (ja nende vorme) vōi kasutatakse taolisi võõrpuuliike, mis ületavad kohaliku dendrofloora esindajad eelkõige oma tootlikkuse ja puidu heade omaduste poolest. Selliste hulka kuulub Eesti NSV tingimustes lehis. Käesolevas artiklis käsitletakse lähemalt laialdasema levikuga sukatšovi lehist ${ }^{1}$ (Larix sukaczevii Dyl.) ja suurema esinemissagedusega euroopa lehist (Larix decidua Mill.). Et Eestis sukatšovi lehist kultiveerida tasub, selles olid meie metsakasvatajad (Raekson, 1921; Schabak, 1922; Rühl, 1926; Auksmann, 1931 jt.) veendunud juba amımu. Käesoleval ajal on jôutud nii Eesti NSV-s kui ka naabermaades Läti NSV-s ja Soomes - arvamusele, et sukatšovi ${ }^{2}$ ja euroopa lehist tasub viia massiliselt metsakultuuridesse (Paivel, 1957; Мауринь, 1954; Heikinheimo, 1956; Margus, 1958a, b jt.).

Lehise kultiveerimine Eestis ulatub XVIII sajandi esimesse poolde (Laas, 1956). Uldse on Eestis lehisekultuure rajatud üle 1000 ha, neist rõhuv enamus pärast Teise maailmasõja lōppu.

Et tagada laialdasemat ja edukamat lehise kasvatamist, on vaja lahendada veel palju küsimusi. Tuleks näiteks jätkata lehisele sobivate kasvukohtade väljaselgitamist, mida seniste tähelepanekute järgi peaks leiduma märksa rohkem. Uhtlasi tuleks edasi uurida lehise kasvatamise võtteid ja laiendada sobivate liikide, eriti teisendite valikut.

Lehise kultiveerimiseks on peetud kõige kohasemaks saviliiv- ja kergeid liivsavimuldi (Tuiskvere-Tiismann, 1936; Timofejev, 1953; Laas, 1956 jt.). Eriti on soovitatud silmas pidada muldade head õhustatavust ja lubjarikkust (Mathiesen, 1934; Timofejev, 1953).

Eelistatumaid lehise kasvualasid on tuultele avatud nōlvad (Frölich, 1955). Oldiselt tulevad arvesse männi ja kuuse parimad kasvukohad (Eichwald, 1953). Lehise kultiveerimise kogemused (eriti sõjajärgseil aastail) näitavad, et teda võib rahuldava eduga kasvatada ka märksa kehvemail

1 Varem sukatšovi ja siberi lehist ei eristatud, mistōttu Eestis esinevaid sukatšovi lenise puistuid nimetati tavaliselt siberi lehise puistuiks (Laas, 1956).

2 Soomes esineb siberi lehise nimetuse all. 
kasvukohtadel. Viimaste all, nagu kohalikud metsateadlased juba mõnikümmend aastat tagasi kogesid, ei tule mõista äärmusi - ei kuivi liivaalasid ega kohti, kus pōhjavesi asub liiga kõrgel (soostunud kasvukohad). Seevastu värsketel liivmuldadel on lehist juba rahuldavate tulemustega kasvatatud. Omal ajal on liivmuldadel kasvatamise võimalustele viidanud R. Riisberg (1933) ja kruusastele kasvukohtadele juhtinud tähelepanu A. Mathiesen (1934).

Lehist võib edukalt kultiveerida väljaspool metsamaid. Enne Esimese maailmasõja puhkemist oli agraarkriisi tõttu tihtipeale lehisekultuure rajatud endistele, sageli üsna viljakatele põllumaadele, kuigi seda ei saa rahvamajanduslikult öigeks tunnistada. Seevastu on otstarbekas metsastada pöllumajanduslikult vähetootlikud maad.

Nii asub meie vabariigi vanim lehisepuistu (rajatud 1812. a.) Vigala metskonna Hirveaia metsas ( 1,8 ha suurusel pindalal) D. Girgidovi andmeil (1951) endisel pōllumaal. Mullaerimiks on siin värske huumuslik savise aluspõhjaga liivmuld (Nissen, 1933). Puistus esinevad nii euroopa kui ka sukatšovi lehis. VI vanuseklassis ületas lehisepuistu sama vana kuusepuistu tagavara kahekordselt (Haller, 1931). 135 aasta vanuselt oli puistu kõrgus $33 \mathrm{~m}$, diameeter rinna kõrgusel $48 \mathrm{~cm}$ ja üldtagavara $1609 \mathrm{tm} / \mathrm{ha}$ (Michelson, 1950). Viimased mōōtmised on näidanud, et maksimaalne puude kõrgus on $38 \mathrm{~m}$ ja diameeter rinna kõrgusel $97 \mathrm{~cm}$ (Paivel, 1957).

Ka vabariigi ilusaim lehisepuistu Loodi metskonnas Püstmäel on rajatud 1820. aastal endisele põllumaale. Puistu asub seljarohu-naadi kasvukohatüübis nõrgalt leetunud kamar-leetmullal, värskel huumuslikul liivsavil. Alustaimestikus esinesid 1957. a. ekspeditsiooni andmeil metspipar (Asarum europaeum L.), maarjasõnajalg (Dryopteris filix-mas (L.) Schott.), metsmaasikas (Fragaria vesca L.); alusmetsas aga - mustsõstar (Ribes nigrum L.), toomingas (Prunus padus L.), pihlakas (Sorbus aucuparia L.), pihl-enelas (Sorbaria sorbifolia (L.) A. Br.), magesõstar (Ribes alpinum L.); lagendikul - valgelepp (Almus incana (L.)); suuremas häilus - harilik vaher (Acer platanoides L.). Puistu on rajatud Saksamaalt Harzist (?) pärinevast euroopa lehise seemnest (Tuiskvere-Tiismann, 1936). 130 a. vanuselt oli puistu kõrgus $33 \mathrm{~m}$, diameeter rinna kõrgusel $46 \mathrm{~cm}$, tagavara $1128 \mathrm{tm} / \mathrm{ha}$ (Гиргидов, 1951).

Endise Kõnnu mõisa ligidale värske liivmullaga kunagisele põllumaale on rajatud lehisekultuur, mille tagavara 35 a. vanuselt oli $292 \mathrm{tm} / \mathrm{ha}$ (Rühl, 1926).

Ka praeguses Eesti Põllumajanduse Akadeemia ōppe- ja katsemetsamajandis Järvseljal on Haavametsa ja Rõkka vahtkonnas rajatud endistele põllumaadele lehisekultuure, mis kasvus ületasid kõrvalolevaid mände ja kuuski (Haller, 1929).

Kui ajavahemikus 1812 -1940 rajati lehisekultuure umbes 145 ha, millest on säilinud 32 ha (Laas, 1955), siis aastail 1947-1958 on neid rajatud 779 ha. 1959. a. rajatud lehisekultuuride pindala on mittetäielikel andmeil kaugelt üle 100 ha. Palju on lehist kultiveeritud Tartu, viimastel aastatel ka Elva metsamajandis.

Ka pärast sõda on lehist kultiveeritud ulatuslikult väljaspool metsamaid, nimelt põllumajanduslikuks kasutamiseks vähesobivatel aladel, nende huigas endistel kehvadel pōllumaadel.

Tartu metsamajandi Vesneri metskonna Tõlgu vahtkonnas kv. 246 on 1949. a. väljapoole metsamaad 3,0 ha suurusele pindalale rajatud sukatšovi lehise ja kuuse segakultuur kujunenud üheks ilusamaks seda laadi lehisekultuuriks. 
Elva metsamajandi lehisekultuuridest on suur osa rajatud väljapoole metsamaid. Uhelt poolt on selleks kasutatud kehvi põllumaid, teiselt poolt - mitmesuguseid järsunõlvalisi või väikesi põllumassiividest lahusolevaid osatükke, mille harimine põlluks, vaatamata rahuldavale mullaviljakusele, pole sotsialistliku suurpõllunduse tingimustes otstarbekas.

Kõige rohkem on lehist kultiveeritud kõnesoleva metsamajandi Otepää metskonnas. 1950. ja 1951. a. rajati lehisekultuure 32 ha. Vahepeal see näitaja mõnevõrra langes, kuid 1957. ja 1958. a. tõusis ta jälle 28 hektarile (Rosanov, 1958). Kultuurid rajati nii, et suuremad lehisesalgad vaheldusid kuuse- ja männisalkadega. Sama metsamajandi Peedu metskonna Keeri vahtkonnas istutati 1951. a. lehist ja kuuske üksikute taimedena männikultuuride hulka.

\section{Jărgnevalt vōtame lăema}

Tabel 1 vaatluse alla 1951. a. lehise-

\section{Metsakultuurid kamar-leetmuldade mitmesuguseil} erimeil 8. kasvuaastal

(Puukesed enamikus 10 aasta vanused)

\begin{tabular}{|c|c|c|c|}
\hline Puuliik & $\begin{array}{c}\text { Kõrgus } \\
\text { (m) }\end{array}$ & $\begin{array}{c}\text { Aasta kesk- } \\
\text { miste kőrguse } \\
\text { juurdekas- } \\
\text { vude } 5 \text { a. } \\
\text { keskmine } \\
\text { (cm) }\end{array}$ & $\mid \begin{array}{c}\text { Diameeter } \\
1,3 \mathrm{~m} \text { kōrgusel } \\
(\mathrm{cm})\end{array}$ \\
\hline
\end{tabular}

\section{Kuival liivmullal (Pööril)}

\begin{tabular}{l|l|l|l} 
Lehis & 3,1 & 64 & 4,7 \\
Mänd & 2,5 & 47 & 3,9 \\
Kuusk & 1,6 & 29 & 1,1 \\
Kask & 3,3 & - & 3,0
\end{tabular}

Värskel savikapõhjalisel liivmullal (Miilimäel)

\begin{tabular}{l|l|l|l} 
Lehis & 4,3 & 68 & 5,8 \\
Mänd & 2,6 & 21 & 3,3 \\
Kuusk & 2,4 & 41 & 2,0 \\
Kask & & & \\
$\quad$ (külvist) & 3,9 & - & 3,7
\end{tabular}

Värskel saviliivmullal (Juksimäel)

\begin{tabular}{l|l|l|l} 
Lehis & 3,5 & 53 & 3,5 \\
Mänd & 2,7 & 45 & 3,3 \\
Kuusk & 2,2 & 39 & 1,6 \\
$\begin{array}{l}\text { Kask } \\
\text { (külvist) }\end{array}$ & 3,0 & - & 2,7
\end{tabular}

Värskel savi- ja liivsavimullal (Savimäel)

\begin{tabular}{l|l|r|r} 
Lehis & 3,4 & 54 & 3,1 \\
Mänd & 2,6 & 44 & 2,9 \\
Kuusk & 3,1 & 50 & 2,7 \\
Kask & & & \\
(külvist) & 5,0 & - & 4,0 \\
Tamm & 1,3 & 20 & - \\
Vaher & 0,2 & 3 & - \\
Jalakas & 0,3 & 5 & -
\end{tabular}

kultuurid neil Elva metsamajandi kasvualadel, mis asuvad väljaspool metsamaid, ja võrdleme seal lehise kasvu kohalike puuliikidega.

Peedu metskonna Keeri vahtkonna I $\left(\mathrm{Pööri}^{3}\right)$ ja II (Miilimäe) katsealale rajati okaspuukultuurid 2-aastaste seemikute istutamisega (12 500-14500 taime ha-le) suuremalt osalt täiskünniga, vähemas ulatuses lappidena (mõõtmetega $1 \times 1 \mathrm{~m}$ ) ettevalmistatud maale. I katsealale istutati ka kaske 2-aastaste metsikute taimedena; II katsealale aga sugenes üksikuid kaski. kultiveerimisaastal looduslikust külvist.

Otepää metskonna Pilkuse vahtkonnas kv. 146 ja 149 (Juksimäe) ning kv. 134 (Savimäe) hariti maa ülepinnaliselt ja istutati 2 -aastased seemikud (8000 taime ha-le) kiilumise teel.

Kultuurid mõōdeti 1958. a. augustis ja oktoobris nende 8. kasvuaastal. Et nende rajamisel oli tarvitatud 2-aastast istutusmaterjali, olid puukesed tegelikult 10 aasta vanused (tab. 1).

Vaadeldavate kultuuride kasvukohatingimused on järgmised.

Peedu metskonna katsealadel esineb nõrgalt leetunud kamar-leetmuld.

a Siin ja edaspidi on sulgudes toodud katseala kohalik nimetus. 
Peedu metskonna Keeri vahtkonna I katseala tüüpiline mullaprofiil:

$\mathrm{A}_{1}, 0-18 \mathrm{~cm}$, hall keskmise kuni peene terajämedusega liiv, $\mathrm{pH} \mathrm{n} \mathrm{KCl}$ 4,2-5,5 (künnikiht, kuiv);

BC, $18-60 \mathrm{~cm}$, pruunikaskollane liiv;

C, $60-100 \mathrm{~cm}$, eelmise horisondi omast heledam liiv.

Liiv liival.

Alustaimestik (kultuuri rajamise aasta kevadsuvel) : põldpuju (Artemisia campestris L.) 2.2, kevad-kadakkaer (Cerastium semidecandrum L.) 2.4, väike oblikas (Rumex acetosella L.) 2.2, Ceradoton purpureus (L) Brid. 4.5.

Peedu metskonna Keeri vahtkonna II katseala tüüpiline mullaprofiil:

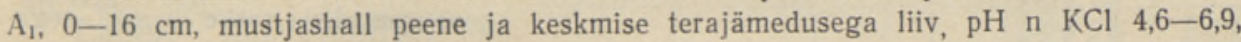
(künnikiht, kuiva ja värske vahepealne);

$\mathrm{BC}, 16-60 \mathrm{~cm}$, pruunikaskollane liiv;

C, $60-100 \mathrm{~cm}$, punakaspruun liivsavi.

Liiv liivsavil. Põhjavesi suvel on sügavamal kui $5 \mathrm{~m}$.

Alustaimestik (kultuuri rajamise aasta kevadsuvel): harilik orashein (Agropyron repens (L.) PB) 3.5, pōldohakas (Cirsium arvense (L.) Scop.) 2.2, pōld-kadakkaer (Cerastium arvense L.) 2.3.

Otepää metskonna katsealadel esineb keskmiselt või nõrgalt leetunud kamar-leetmuld.

Otepää metskonna Pilkuse vahtkonna kv. 146 katseala tüüpiline mullaprofiil:

A:. $\quad 0-18 \mathrm{~cm}$, hall saviliiv (künnikiht, värske);

$\mathrm{A}_{2}, \quad 18-45 \mathrm{~cm}$, kollakashall saviliiv;

B. $45-95 \mathrm{~cm}$, punakaspruun kerge liivsavi;

BC, 95-100 cm, karbonaatne punakaspruun, porsunud, paetükke sisaldav liivsavi-moreen. Saviliiv liivsavil.

Alustaimestik (kultuuri rajamise aasta kevadsuvel): tavalised pōlluumbrohud (Margtis, 1957),

Otepää metskonna Pilkuse vahtkonna kv. 134 katseala tüüpiline mullaprofiil:

$\mathrm{A}_{1}, \quad 0-2 \mathrm{~cm}$, mustjas struktuuritu savi ja liivsavi (kamara-alune kiht, värske);

$\mathrm{BC}, 2-40+\mathrm{cm}$, tugevasti tihenenud punakaspruun savi.

Savi ia liivsavi savil.

Alustaimestik (kultuuri rajamise aasta kevadsuvel): tavalised pōlluumbrohud.

Lehis kasvas kuival liivmullal esialgu küll sama kiiresti või kiireminigi kui mänd, ent taimede väljalangemine tema puhul oli üsna suur. Seetõttu jääb niisugustel kasvukohtadel peapuuliigiks ikkagi mänd. Värskesse savikapõhịalisse liivmulda istutatud lehise säilivus kui ka kasv olid head. Samuti oli lehisel üsna hea kasv värskel saviliivmullal, mida on peetudki sellele puuliigile kõige sobivamaks pinnaseks. Võrdlemisi hästi kasvas lehis ka künkliku reljeefiga savi- ja liivsavimullal. Suhteliselt raskemail mullaerimeil hakkab kuusk siiski suuremat tähtsust omandama, tõrjudes kõrvale lehise.

Välismaa kogemustel on euroopa lehist soovitatud kultiveerida mitte ainult optimaalseis tingimustes, vaid ka kehvemates kasvukohtades (Frölich, 1955).

Saaremaa metsamajandi Kangruselja metskonna Uuelõve vahtkonnas on lehist katsekorras kultiveeritud pōllumajanduslikult vähetootvail lagedail looaladel. Teda on istutatud 1955. a. kevadel 2-aastaste seemikutena kiilumise teel (seadus 1,5 $\times 1,0 \mathrm{~m}$ ) lapiti kõrvalepööratud mätastele (mõõtmetega $0,5 \times 0,5 \mathrm{~m}$ ). Võrdluseks istutati samadel tingimustel mändi, kuuske, kaske ja teisi puuliike. Kõiki neid kultuure inventeeriti 1958. a. sügisel, s. o. kultuuride 4. kasvuaastal (puukesed ise olid siis 6 aastat vanad, vt. tab. 2).

Viimati vaadeldud katseala asub ōhukesel tüüpilisel kamar-karbonaatmullal. 
Tabel 2 Kasvukoha tüüpiline mullapro-

Metsakultuurid õhukesel tüüpilisel kamar-karbonaatmullal 4. kasvuaastal

(Puukesed 6 aasta vanused)

\begin{tabular}{l|c|c|c|c}
\hline \multicolumn{1}{c|}{ Puuliik } & $\begin{array}{c}\text { Korda- } \\
\text { mineku } \\
\text { \% }\end{array}$ & $\begin{array}{c}\text { Koorgus } \\
\text { (cm) }\end{array}$ & $\begin{array}{c}\text { Kórguse } \\
\text { juurde- } \\
\text { kasv vii- } \\
\text { masel aas- } \\
\text { tal (cm) }\end{array}$ & $\begin{array}{c}\text { Diameeter } \\
\text { juure- } \\
\text { kaelal } \\
\text { (cm) }\end{array}$ \\
\hline Lehis & & & & \\
(euroopa) & 74 & 78 & 27 & 1,0 \\
Mänd & 85 & 25 & 9 & 0,5 \\
Kuusk & 33 & 15 & 3 & 0,4 \\
Kask & 63 & 58 & - & 1,0
\end{tabular}

fiil E. Kaare (1958) andmeil on järgmine:

$A_{1}, 0-15 \mathrm{~cm}$, hallikaspruun keskmine liivsavi (kuiv, keskmiselt juurestunud);

$\mathrm{A}_{1} \mathrm{C}^{\prime}, \quad 15-40 \mathrm{~cm}$, kollakaspruun sõmeraline rähane moreen rohkete dolomiidi tükikestega;

$\mathrm{A}_{1} \mathrm{C}^{\prime \prime}, \quad 40-55 \mathrm{~cm}$, kollakasvalge roostepesadega raske liivsavi, segatud rohke rähaga;

C, $55+\mathrm{cm}$, paerähk.

«Keemine» algab $15 \mathrm{~cm}$ sügavusel.

Alustaimestik: harilik kortsleht (Alchemilla vulgaris L.) 1.1, kassi-

käpp (Antennaria dioica (L.) Gaertn.) 1.2, arukaer (Avena pratensis L.) 1.1, harilik värihein (Briza media L.) 1.1, angervaks (Cynachum vincetoxicum (L.) Pers.) 1.3, angerpist (Filipendula hexapetala Gilib.) 1.1, värvmadar (Galium boreale L.), 1.1, hobumadar (Galium verum L.) 1.1, lubikas (Sesleria coerulea (L.) Ard.) 1.2, nōmme-liivatee (Thymus serpyllum L.) 1.2, pōõsarindes harilik kadakas (Juniperus communis L.) 2.2, kõrgusega $0,5-1,0 \mathrm{~m}$, täiusega $0,3-0,4$, endisel karjamaal.

Nagu inventeerimisandmed näitavad, on viimati käsitletud kasvukohatingimustes osutanud parimat kasvu lehis ja teda võib männi kõrval edukalt arvestada peapuuliigina. Head kasvu kõnesolevatel aladel on näidanud veel kask. Lehis on andnud rahuldavaid tulemusi ka huumus-karbonaatmuldadel, kui peeneselise mullakihi tüsedus on ulatunud $20-30 \mathrm{~cm}$ (Kaar, 1958).

Lehise kasv rahuldava mullaviljakusega, kuid järsunôlvalisuse tōttu harimiseks sobimatul, endisel põllumaal pole palju halvem kui metsamaal. Seda tõendab Otepää metskonna Arula vahtkonnas kv. 112 väljaspool metsamaad 1,2 ha suurusel pindalal kasvava 9-aastase lehisekultuuri võrdlus teise sama vana 0,8 ha suuruse kultuuriga, mis asub sama metskonna Pilkuse vahtkonnas kv. 133 endisel raiestikul (tab. 3).

Esimesel juhul on kultiveeritud 1950. aasta kevadel 2-aastaste seemikute kiilumisega (seadus $1,2 \times 1,3 \mathrm{~m}$ ) täisharitud maale; teisel juhul on istutatud (seadus $1,2 \times 1,2 \mathrm{~m}$ ) sama vanad seemikud lappidena (mõōtmetega $0,5 \times 0,5 \mathrm{~m}$ ) ettevalmistatud maapinnale.

Kasvukohaks oli nörgalt leetunud kamar-leetmuld.

Esimesc kultuuri mullaprofiil (Margus, 1957):

$A_{1}, 0-13 \mathrm{~cm}$, hall kerge liivsavi (künnikiht; värske);

$\mathrm{A}_{2} \mathrm{~B}, 13-33 \mathrm{~cm}$, valkjaspruun saviliiv;

BC, 33--8? cm, punakaspruun üksikute paetükkidega keskmine liivsavi-moreen, sisaldab raudkive ja paetükke;

C, $87-100 \mathrm{~cm}$, ülemises osas valkjashall raske liivsavi kuni savi.

Keskmiselt erodeeritud, kerge liivsavi keskmisel liivsavi-moreenil.

Alustaimestik: kerahein (Dactylis glomerata L.), punane aruhein (Festuca rubra L.), harilik hiirehernes (Vicia cracca L.), äiatar (Knautia arvensis (L.) Coult).

Teise kultuuri mullaprofiil:

$\mathrm{A}_{1}, \quad 0-20 \mathrm{~cm}$, hallikasmust teralise struktuuriga saviliiv (värske);

$\mathrm{A}_{2} \mathrm{~B}, 20-40+\mathrm{cm}$, kollakashall saviliiv.

Alustaimestik peaaegu puudus kultuuri täieliku liitumise tôttu. 
Eespool kirjeldatud kasvukohtadele istutati lehisega üheaegselt ning võrdsetes tingimustes kuuske - endisele põllumaale 4-aastaste istikutena, metsamaale 3-aastaste seemikutena. Ulevaate mōlema puuliigi kasvu kohta nii endisel põllumaal kui ka metsamaal annab tabel 3.

Esitatud tabelist selgub, et lehisekultuuride kasv on mōlemal juhul tugev, metsamaal siiski veidi parem kui endisel põllumaal. Kuuse kõrguskasv on raiestikul märksa tugevam.

Lehise kasvatiamisel on olnud üheks põhiliseks küsimuseks puht- või segakultuuride kasutamine.

M. Sivers soovitas 1892 . a. peetud ettekandes ainult lehise puhtpuistuid (Rühl, 1926). Sama ettepaneku tegi ka F. Berg (1924). Uldiselt ongi vanimad Eesti lehisekultuurid rajatud enamikus puhtkultuuridena (Laas, 1955). Oks väheseid omaaegseid metsateadlasi, kes propageeris le-

Tabel 3

Euroopa lehise ja kuuse kasv endisel põllumaal ja raiestikul kultuuride 9 . kasvuaastal

(Lehised 11-aastased, kuused 13- ja 12-aastased)

\begin{tabular}{|c|c|c|c|c|}
\hline $\begin{array}{l}\text { Kasvukoht ja } \\
\text { puuliik }\end{array}$ & 这苞 & 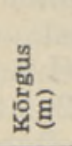 & 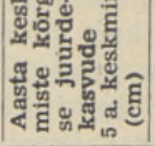 & 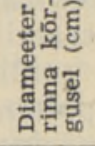 \\
\hline $\begin{array}{c}\text { Endisel } \\
\text { põllumaal }\end{array}$ & & & & \\
\hline $\begin{array}{l}\text { Lehis } \\
\text { Kuusk }\end{array}$ & $\begin{array}{l}79 \\
99\end{array}$ & $\begin{array}{l}4,3 \\
2,7\end{array}$ & $\begin{array}{l}50 \\
51\end{array}$ & $\begin{array}{l}5,1 \\
2,3\end{array}$ \\
\hline Raiestikul & & & & \\
\hline $\begin{array}{l}\text { Lehis } \\
\text { Kuusk }\end{array}$ & $\begin{array}{l}79 \\
95\end{array}$ & $\begin{array}{l}4,9 \\
3,6\end{array}$ & $\begin{array}{l}69 \\
54\end{array}$ & $\begin{array}{l}4,8 \\
2,2\end{array}$ \\
\hline
\end{tabular}

hise ja kuuse segakultuure, oli E. Schabak (1922). Ka Soomes on pärast Teise maailmasõja lõppu väidetud, et lehisel (siberi) on parim kasv puhtais üheealisis puistuis (Stanek, 1954). Mitmed nõukogude metsateadlased on viimasel ajal soovitanud kultiveerida lehist (euroopa) kas puht- või segakultuuridena (Гиргидов, 1951). V. Timofejev (1953) peab võimalikuks kultiveerida teda küll mõlemat moodi, kuid eelistab segakultuure.

Tegelikult on Eestis 1950-ndatel aastatel rajatud küllalt lehisekultuure kas täiesti puhtkultuuridena või ainult vormiliselt segakultuuridena, kus ta vähemate või suuremate osatükkidena vaheldus teiste puuliikidega.

Käesoleval ajal tuleks lehise puhtkultuuride rajamisse suhtuda eitavalt, sest need on hakanud tugevasti kannatama seenhaiguste, eriti lehisevähi all. Selle pōhjustajaks üldiselt on ketasseen Dasyscypha willkommii Hart., mis nakatab puid peamiselt kuivanud okste kaudu, kust tungib edasi elavasse tüvesse, muutub saprofüüdist parasiidiks ja tekitab tüvel vähihaavandeid. Mütseel vegeteerib koores rakkude vahel, kust ta puiduni tungides surmab kambiumi. Kahjustuskohal kuivab koor ja esineb ka vähest vaigujooksu. Surnud koorel arenevad mõnemillimeetrise läbimõõduga alustassikujulised valged viljakehad (apoteetsiumid).

Lehisevähk on Lääne- ja Kesk-Euroopas tavaline lehise haigus, mis esimest korda avastati Alpides.

Eestis märgiti lehisevähki esmakordselt 5. X 1941. a. Järvseljal. 1943. aastaks oli registreeritud 7 lehisevähi esinemisjuhtu - neist 5 euroopa, 1 siberi (resp. sukatšovi) ja 1 tundmatul lehiseliigil (Ostrat, 1943). Aasta hiljem avastati samas kohas mõlemal esimesel puuliigil märksa enam lehisevähki ja 4 juhul esines kahjustus ka kuriili lehisel (Ostrat, 1944). Uldiselt polnud lehisevähk Eesti territooriumil tookord eriti laialdaselt levinud. Põhjust seletas A. Ostrat (1943) sellega, et lehisekultuurid asusid meil väikestel pindaladel ja domineeris siberi lehis (resp. sukatšovi lehis), mis Eesti kliimas on vähi suhtes ímmuunsem. Omaaegses kohalikus metsanduslikus kirjanduses väideti, et lehis, sealhulgas ka euroopa lehis, ei 
kannata nimetamisväärselt seenhaiguste ja putukkahjurite all (Riisberg, 1933). E. Viirok (1928) märkis koguni, et euroopa lehis pōhjapoolseis piirkondades vähktõbe ei põe. Sellised seisukohad lehise heast vastupidavusest seenhaigustele, kaasa arvatud lehisevähi tekitajale, on püsinud tänapäevani (Гиргидов, 1949; Timofejev, 1953; Paivel, 1957).

Viimastel aastatel on lehisevähi esinemisjuhte registreeritud Järvseljal Eesti Põlumajanduse Akadeemia ōppe- ja katsemetsamajandis, Kaarepere ja Roela metskonnas (Muiste, 1957).

Kirjanduse andmeil tabab lehisevähk tavaliselt 10-40-aastasi puistuid (harilikult II vanuseklassist, seega ca 20-ndais ja 30-ndais kasvuaastais). Noorim puuke, mida lehisevähk 1943. aastal Järvseljal kahjustas, oli erandlikult 11-aastane.

Mis puutub lehisevähi levikusse meie naaberaladel, siis näiteks Lätis polnud kuni 1932. aastani selle kohta andmeid (Ostrat, 1943). Soomes pärineb esimene Dasyscypha willkommii Hart. leid 1924. aastast. Suure haruldusena on lehisevähi tekitajat registreeritud $60 \mathrm{~cm}$ kõrgusel puukesel. Hiljem on Soomes seda seenhaigust piiratult noteeritud, üldiselt II-III vanuseklassi puistuis (Kujala, 1950).

Massilist lehisevähi kahjustust alla 10-aastastes lehisekultuurides on registreeritud esmakordselt 1958. a. Elva metsamajandis. Nähtavasti hakkas seenhaigus ulatuslikult levima seetõttu, et lehise kultiveerimine puhtkultuuridena laienes. Eriti märgatavaks kujunes see kahjustus Otepää metskonnas põllumajanduslikuks kasutamiseks vähesobivaile aladele rajatud noortes lehisekultuurides.

Bioloogiateaduste kandidaat E. Parmasto (ENSV TA Zooloogia ja Botaanika Instituudist) tegi kindlaks, et lehisevähki põhjustab seenhaigus, mille tekitab Dasyscypha villkommii Hart. (Selle kõrval esineb veel teisi seenhaigusi, mille lõplikuks väljaselgitamiseks on vaja uurimistöid lehisekultuurides jätkata.)

Mis puutub lehisevähi levimisse Otepää metskonnas, siis täheldati selle massilist esinemist kultuuride 8. ja 9. kasvuarastal. Nii oli 1958. a. sügisese inventeerimise andmeil põllumajanduslikult vähesobivaile aladele Arula vahtkonnas kv. 112 rajatud lehisekultuuris vähihaavandiga puid $22 \%$, Pilkuse vahtkonnas kv. 133 metsamaal asuvas lehisekultuuris $17 \%$. Väiksem kahjustusprotsent viimasel juhul võis olla tingitud kultuuri veidi jõudsamast kasvust. Arula vahtkonnas avastati augustikuus mõned Dasyscypha willkommii Hart, viljakehad.

Pilkuse vahtkonnas kv. 146 ja 149, kuhu lagedaile mitmesuguse mullastikuga mittemetsamaadele (domineerivad nōrgalt leetunud kamar-leetmullad, mullaerimilt värsked saviliivmullad) 1951. a. kevadel on istutatud väikeste osatükkidena üle 10 ha lehisekultuure vahelduses männi ja kuusega, oli 1958. a. sügisel säilinud ca $40 \%(24-50 \%)$ puukesi, millest ca $30 \%(21-45 \%$, lohkudes ka enam) olid vähihaavandiga. Dasyscypha willkommii Hart. viljakehi leidus seal väga vähe. 1959. a. mais aga esines neid juba ühel neljandikul kahjustatud puukestel. Nõlvakuil ja reljeefi kōrgemail osadel oli kahjustus väiksem kui reljeefi madalamais osades. Niisketes lohkudes olid puukesed valdavas osas hukkunud, üksikud veel elusad eksemplarid aga olid enamikus vähihaavanditega. Taolisi andmeid on ka Kambja metskonnast. Kirjanduseski märgitakse, et lehis, eriti euroopa !ehis, kannatab madalamais kohtades tugevasti vähikahjustuse all (McComb, 1955). D. Girgidovi (1955) andmeil on seenhaigus tugevam rasketel muldadel kasvavail lehistel.

Esialgsed kogemused näitavad, et lehise ja okaspuude segakultuurides, kus lehist esineb suhteliselt hajusalt, on tema tervislik seisund alati parem. On aga teada, et lehis üsna hōlpsasti saab valitsevaks puuliigiks ja moo- 
dustab hõreda ülarinde. Hõredas ülarindes kasvab lehis soodsalt. Lehisele soovitatavate segupuuliikide hulka kuuluvad: pärn, vaher, kuusk, künnapuu, saar, mänd, siberi nulg, pōhja tamm jt. (Timofejev, 1953). Taani kogemustel on kõige vastupidavamad haigustele just lehise ja nulu segapuistud (Hendriksen, 1955). Omal ajal soovitas E. Schabak (1922) lehise ja kuuse segakultuure, kus üks puuliik vahelduks teisega ridade viisi. Suhteliselt kehvemais kasvukohatingimustes aga tuleb lehise seguliigina arvesse mänd. Viimast on soovitanud mitmed NSV Liidu ja välismaa metsateadlased (Коновалов, 1956; McComb, 1955) ning see on leidnud kinnitust ka Eesti NSV tootmiskogemustes. Ka lehise ja männi segakultuuris pääseb lehis järk-järgult valitsema, mida soodustab muu hulgas ta külgjuurte hoogus arenemine (Лебдик, 1954).

Taolise segakultuuri näiteks on Otepää metskonna Palupera vahtkonnas endise Kriska talu maal 1954. a. kevadel rajatud kultuur. Seal vaheldub üks rida lehist 3 rea männiga, kusjuures lehiseridades lehis omakorda vaheldub kikkapuuga. Istutus rajati 2 -aastaste seemikute kiilumisega üleniharitud maale, mis oli ette valmistatud traktorikünni ja randaalimisega. Istutusseaduks oli $1 \times 1,25 \mathrm{~m}, \mathrm{~s}$. o. 8000 taime hektarile; neist 6000 oli mändi, 1000 lehist ja 1000 kikkapuud.

Kõnesolev kasvukoht asub nōrgalt leetunud kamar-leetmullal.

Kasvukoha mullaprofiil (nõlvaalusest kohast) on järgmine:

$A_{1}, 0-20 \mathrm{~cm}$. hallikasmust väikeseteralise struktuuriga keskmine saviliiv (künnikiht, värske):

$A_{1} A_{2}, 20-30 \mathrm{~cm}$, pruunikaspunane heledamate pesadega struktuurifu, tugevasti tihenenud keskmine saviliiv (värske kuni kuiv);

B, $30-55 \mathrm{~cm}$, eelmisest punakam, tugevasti tihenenud keskmine saviliiv;

C, $55+\mathrm{cm}$. kollane kerge saviliiv, hulgas raudkivi-rähka.

Saviliiv saviliival.

Alustaimestikus tavalised põlluumbrohud.

1958. a. sügisel näitas kultuur head kasvu (tab. 4). Vähihaavandiga lehiseid esines vaid $1-5 \%$.

Ka Peedu metskonna Keeri vahtkonna I ja II katsealal, kus 1951. a. kevadel istutati lehist üksikute eksemplaridena männikultuuridesse, olid lehised täie tervise juures.

Lehisekultuuride tervislikule seisundile avaldab teataval määral mõju ka istutussead. Nimelt on täheldatud, et hõredama seadu puhul on lehisevähi kahjustus

Tabel 4

Lehise, männi ja kikkapuu segakultuuri kasv värskel saviliivmullal 5, kasvuaastal

(Puukesed 7 aastat vanad)

\begin{tabular}{l|c|c|c|c}
\hline \multicolumn{1}{c|}{ Puuliik } & $\begin{array}{c}\text { Korda- } \\
\text { mineku } \\
\%\end{array}$ & $\begin{array}{c}\text { Korgus } \\
(\mathrm{m})\end{array}$ & $\begin{array}{c}\text { Korguse } \\
\text { juurde- } \\
\text { kasv vii- } \\
\text { masel } \\
\text { kasvu_ } \\
\text { aastal } \\
\text { (cm) }\end{array}$ & $\begin{array}{c}\text { Diameeter } \\
\text { juure- } \\
\text { kaelal } \\
\text { (cm) }\end{array}$ \\
\hline $\begin{array}{l}\text { Lehis } \\
\text { (euroopa) }\end{array}$ & 95 & 1,70 & 50 & 2,9 \\
$\begin{array}{l}\text { Mänd } \\
\text { Kikkapuu }\end{array}$ & 82 & 0,84 & 30 & 1,7 \\
& 93 & 0,51 & - & 3,4
\end{tabular}

väiksem. Nii on soovitatud kultiveerida 5000-10000 taime hektarile folenevalt kasvukohast - M. M.), neist 1000-2000 lehist (Timofejev, 1953). R. Riisberg (1933) märgib, et häid tulemusi on andnud nii 2-aastaste seemikute kui ka 4-5-aastaste istikute kasutamine seadus $2 \times 2 \mathrm{~m}$, kuhu lisaks on sugenenud looduslikust külvist lehtpuid, mis aitasid kaasa lehise laasumisele. Tuiskvere-Tiismanni (1936) arvates võib siberi lehist (resp. sukatšovi lehist) kultiveerida seadus $1,5 \times 1,5 \mathrm{~m}$, euroopa lehist aga, mis on valgusnõudlikum, seadus $2 \times 2 \mathrm{~m}$; antud juhtudel oli lehiseridade vahele ette nähtud istutada kuuske, mille tagajärjel taimede arv hektari kohta 
oleks tõusnud 5000-le kuni 7500-le. Soomes on lehist istutatud hea eduga seadus $2,5 \times 2,5 \mathrm{~m}$ (Margus, 1958a).

Oldiselt peab kultuuride sead väljaspool metsamaad asuvail lagedail aladel olema tihedam kui metsamaal, kuhu sugeneb kergemini seguliike.

Lehisekultuurides on kasulik alustada varakult valgustus- ja puhastusraietega, et vältida kuivanud puukeste teket, mis soodustavadki lehisevähi arengut Varajase valgustusraie tähtsust lehise kasvu soodustajana on rōhutatud ammu (Rühl, 1926), ent seda pole seni küllalt tõsiselt arvestatud. Valgustusraietega tuleb alustada juba kultuuri 3. või 4 . kasvuaastal. Lehisel peab olema alati vaba valguse juurdepääs ja võra all kamardumata muld (Timofejev, 1953).

Teistest lehiseliikidest kasvavad meil suhteliselt hästi ja on küllalt terved kuriili ning jaapani lehis.

Saksamaa kogemustel, kus jaapani lehise puistuid esineb arvukalt, on ta osutunud vastupidavaks vähktõvele (Rupf, 1956). Viimasel ajal on Soomes Ruotsinkyläs siiski ette tulnud mõningaid jaapani lehise kahjustusjuhte (Margus, 1958a). Lehisevähi nõrka kahjustust on täheldatud ka kuriili lehisel, millest oli eespool juttu.

Eesti Pôllumajanduse AkaTabel 5 deemia Järvselja ōppe- ja

Mitmesuguste lehiseliikide, männi ja kase segakultuuri kasv 8 . kasvuaastal

(Lehised 12-aastased, männid 10-aastased, kased 8-aastased)

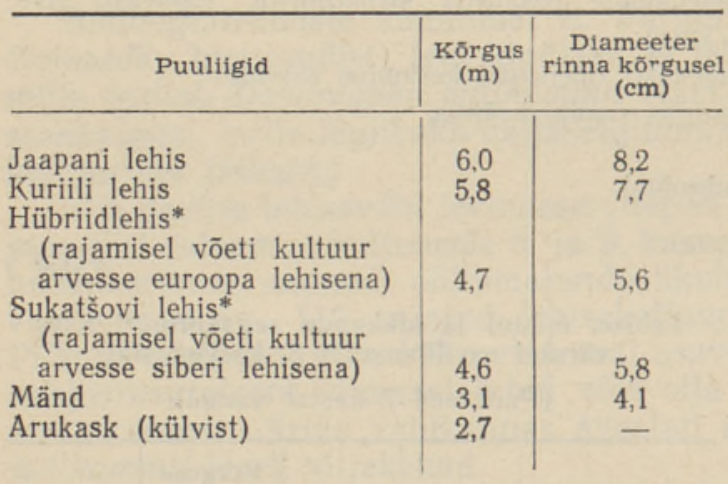

* Lehiseliigid täpsustas E. Laas pärast käbikandvuse algust. sukatšovi lehise kultiveerimisel on suure tähtsusega sobivate rasside valik. Metsateaduslikus kirjanduses on väidetud, et lehisevähile vastupidav on euroopa lehise sudeedi ehk sileesia rass (Tuiskvere-Tiismann, 1936; McComb, 1955; Heikinheimo, 1956), mis on ka sirgema tüvega (Viirok, 1928; Timofejev, 1953), kuna alpi ehk tirooli rass kannatab sageli lehisevähi all. Seda tuleb arvestada lehiseseemnete sissetoomisel. Köige parem on tarvitada kohapealset, aklimatiseerunud lehiste seemet. 


\section{KIRJANDUS}

A u ksmann, A., 1931. Siberi lehis - Larix sibirica. Eesti Mets, nr. 7.

E i chwald, K., 1953. Eesti NSV Floora, I. Tallinn, lk. 113-223.

Frölich, T., 1955. Standortsansprüche der europäischen Lärche. Allgem. Forst- und Jagdzeitung, Nr. 4.

Ha 11 e r. B.. 1929. Kultuurid Tartu Olikooli õppemetskonnas Kastre-Peravallas. Tartu Olikooli Metsaosakonna toimetused, nr. 13.

Haller, B., 1931. Andmeid võōramaa puuliikide kasvatamisvõimaluste kohta välismail ja Eestis. Festi Metsanduse Aastaraamat V. Tartu.

$\mathrm{H}$ e i k i n h e i m o, O., 1956. Tuloksia ulkomaisten puulaiien viljelvstä Suomessa. Helsinki.

Hendriksen. H. A., 1955. Dyrkning af naletrae I Lidt om naletraedyrkning. Holmsgaard Erik 2. Naletraernes produktion og stabilitet. Dansk skovfor tidsskr. № 12.

K a a r, E.. 1958. Saaremaa looalade metsakasvatuslikud omadused ja metsastamise vôimalused. Dissertatsioon bioloogiateaduste kandidaadi kraadi saamiseks. Käsikiri FNSV TA Keskraamatukogus.

Kuja la, V., 1950. Ober die Kleinpilze der Koniferen in Finnland. Helsinki.

$\mathrm{L}$ a a s, E., 1955. Tulemusi lehise kasvatamisel Eesti NSV-s. Loodusuurijate Seltsi Aastarasmat. Tallinn.

L a a s., E. 1956. Uurimus lehise seemnete kvaliteedist ia ntstarbekast kasutamisest Festi NSV-s. Dissertatsioon bioloogiateaduste kandidaadi kraadi saamiseks. Käsikiri FNSV TA Keskraamatukogus.

M a rgus. M.. 1957. Pōllumaianduslikult vähetontlike maade metsastamine Kaqu-Festis. Metsanduslikud uurimused I. ENSV TA Zooloogia ja Botaanika Instituut. Tartu.

Margus. M.. 1958a. Vōörpuuliikide kasvatamisest Soomes. ENSV TA Toimet. Biol. Seeria. nr. 3.

M a r g u s, M., 1958b. Võõrpuuliikide introdutseerimisest Lätis. Sotsialistlik Põllumajandus, nr. 7.

M a thiesen, A., 1934. Dendroloogia, Tartu.

McComb. A. L., 1955. The European Larch: Its Races, Site Requirements and Characteristics. Fnrest Sci., No. 4.

Michels o n. A., 1950. Võõrpuuliikide kasvatamisest Eesti NSV-s. Autori surma tõttu kaitsmata iäänud kandidaadidissertatsiooni käsikiri Eesti Pōllumajanduse Akadeemia metsakasvatuse ja -kultuuride kateedris.

Mu iste, L.. 1957. Lehisevähi esinemine Eesti NSV-s. ENSV TA Toimet. Biol. Seeria, nr. 3.

$\mathrm{N}$ is se n, R., 19.33. Vigala lehisepuistud. Eesti Mets, nr. 5.

Ostrat, A., 1943. Lehisevähi (Dasyscypha Willkommii (Hart.) Rehm) leidudest Eestis. Eesti Mets, nr. 7.

Ostrat, A., 1944. Kuriili lehise (L. Gmelini var. japonica Pilger) kultuurid T. U. õppeia katsemetskonnas. Eesti Mets, nr. 5.

$\mathrm{P}$ a ivel, A., 1957. Läänepoolses Eestis esinevad introdutseeritud okaspuuliigid ja nende kasutamise vōimalused. ENSV TA Toimet. Biol. Seeria, nr. 3.

R a e ks o n, A., 1921. Võõramaa puude asetamisest meie metsadesse. Eesti Mets, nr. 9.

Riisberg, R. 1933. Eriotstarbeliste tarbepuude kultuurid ülikooli ōppe- ja katsemetskonnas. Eesti Mets, nr. 5.

Ros a nov, P., 1958. Otepää metskonna töötajate saavutusi lehisekultuuride rajamisel. Metsamaiandus, juuni.

Rup f, H., 1956. Die japanische Lärche. Holz-Zbl., Nr. 2/3.

R ü h l, A., 1926. Pärnumaal leiduvatest võōramaa puuseltsidest. Tartu Ulikooli Metsaosakonna toimetused, nr. 9.

S ch a b a k, E., 1922. Puuseltside valimisest Eesti metsamajandusele. Eesti Mets, nr. 12

S t a n e k, W., 1954. Der Lärchenwald in Finnland. Holz-Zbl., Nr. 19.

T i m of e jev, V., 1953. Lehise kasvatamine. Tallinn.

Tuiskvere-Ti ismann, B., 1936. Lehis väärib senisest suuremat tähelepanu. Eesti Mets, nr. 4.

Vi i rok, E., 1928. Võōramaa puuliigid meie metskondades. Eesti Mets, nr. 4.

Ги ргидов Д. Я., 1949. Новые древесные породы для разведения в лесах северозапада. Лесн. х-во, № 11.

Ги ргидов Д. Я., 1951. Культура лиственницы европейской в северо-западных областях СССР. Лесн. х-во, № 5.

Ги рг и д о в Д. Я., 1955. Культуры новых хвойных пород в северо-западных районах СССР. Географический сб. V. Географические вопросы лесного хозяйетва. М.-Л. 
Коновалов Н. А., 1956. Лиственница Сукачева в культуре на Среднем Урале. Сб. тр. по лесн. х-ву, Уральский лесотехн. ин-т, вып. 3 .

Л е 6 д и к Ф. П.. 1954. Смешанные культуры лиственниц с сосной. Лесн. х-во, № 1 . М а ур ин ь А. M., 1954. Итоги интродукции новых хозяйственно-ценных древесных и кустарниковых пород в центральных и западных районах Латвийской ССР. Автореферат диссертации на соискание ученой степени кандидата биологических наук. Ленинград.

Eesti NSV Teaduste Akadeemia Zooloogia ja Botaanika Instituut
Saabus toimetusse

6. III 1959

\title{
О КУЛЬТУРАХ ЛИСТВЕННИЦЫ И ИХ САНИТАРНОМ СОСТОЯНИИ В ЭСТОНСКОИ ССР
}

\author{
M. M. Маргус, \\ кандндат сельснохозяйственных наун
}

Резюме

Отдельные опытные и производственные культуры лиственницы, имеющиеся в нашей республике, показывают, что культивирование этих хвойных деревьев в Эстонии можно значительно расширить, создавая ее культуры также вне лесных площадей на различных малопрнгодных для сельскохозяйственного пользования землях. Так, под культуры лиственницы наряду со свежими супесчаными и легкими суглинистыми почвами можно занимать также свежие песчаные почвы на песчаной и, особенно, на глинистой подпочве (слабо и средне оподзоленные дерново-подзолистые почвы, частью также подзолистые почвы), где рост как молодых, так и более старых лиственничных насаждений протекает очень успешно. На всех этих местах произрастания лиственница уже в течение первых десяти лет значительно превосходит в росте сосну и ель, уступая только березе.

Наиболее целесообразно культивировать лиственницу вместе с другими древеснымп породами. В чистых культурах лиственницы моложе 10 лет в 1958 г. замечено массовое поражение раком (возбудитель Dasyscypha willkommii Hart., а, возможно, еще и некоторые другие грибы). Поражение особенно значительно в более низких местах рельефа (во впадинах, котловинах, особенно в сырых местах).

Наибольший очаг поражения раком лиственнищы наблюдался в 1958 г. в обходе Пилькузе лесничества Отепя, где в культурах лиственницы на восьмом году роста (деревца 10-летние) сохранилось $40 \%$, из которых $30 \%$ были поражены раком лиственннцы.

Культивирование лиственницы следует производить соответственно месту произрастания в смеси с елью и сосной (а также с некоторыми лиственными п кустарниковыми породами), причем лиственницу рекомендуется располагать среди других древесных пород рассеянно (не более $1 / 4$ состава).

В культурах лиственницы рубки осветления необходимо начинать рано, так как высохшие деревья ее содействуют распространению рака лиственницы.

По сравнению с лиственницей европейской (Larix decidua) и Сукачева (L. sukaczevii) более стойкими по отношению к раку оказываются лиственница японская (L. leptolepis) и курильская (L. kurilensis), небольшие культуры которых, произрастающие в учебно-опытном лесхозе Эстонской сельскохозяйственной академин, остались совершенно нетронутыми раком лиственницы.

Ннститут зоологии и ботаники Академии наук Эстонской ССР
Поступила в редакцию 6 III 1959 


\title{
OBER DIE LARCHENKULTUREN UND DEREN GESUNDHEITSLAGE IN DER ESTNISCHEN SSR
}

\author{
M. Margus
}

\section{Zusammenfassung}

Einzelne Versuchs- und Produktionskulturen zeigen, dass die Kultivierung der Lärche in Estland merklich ausgedehnt werden kann, indem man diese Baumart auch ausserhalb der Forstböden auf verschiedenen für die Landwirtschaft wenig tauglichen Ländereien anbaut. So können neben den frischen lehmigen Sandböden und den leichten sandigen Lehmböden auch frische Sandböden auf sandigem, besonders aber auf lehmigem Untergrund benutzt werden, wo junge und auch ältere Lärchenbestände gut gedeihen (schwach und mittelmässig podsolierte Rasen-Bleicherdeböden, teilweise auch Bleicherdeböden).

Weite Möglichkeiten gibt es für die Anpflanzung der Lärche auf waldlosen Alvarenböden, wo die Tiefe der feinkörnigen Bodenschicht nicht unter $20-30 \mathrm{~cm}$ ist (typische Rasenkarbonatböden, auch Humuskarbonatböden). Auf allen diesen Standorten übertrifft die Lärche schon während der ersten zehn Jahre den Wuchs der Kiefer und Fichte; schneller wächst bloss die Birke. Es ist zweckmässig, die Lärche als Mischkultur mit anderen Holzarten zusammen zu kultivieren. In reinen Lärchenkulturen im Alter unter 10 Jahren trat im Jahre 1958 der Lärchenkrebs massenhaft auf (dessen Erreger kann Dasyscypha willkommii Hart. sein, möglicherweise aber auch noch andere Pilze). Der Schaden ist besonders gross an den niedrigsten Stellen des Reliefs und in Senken (besonders an feuchteren Stellen). Der grösste Herd des Lärchenkrebses war 1958 im Belaufe Pilkuse der Oberförsterei Otepää, wo die Haltbarkeit der Lärchenkulturen beim 8-jährigen Wuchs (die Bäumchen waren 10 Jahre alt) $40 \%$ war, wobei $30 \%$ der vor. handenen Exemplare Krebswunden aufwiesen.

Je nach dem Standort ist es zweckmässig, die Lärche mit der Fichte und der Kiefer vermischt anzubauen (auch mit einigen Laubbäumen und Sträuchern), wobei sich die Lärche zerstreut zwischen den Mischholzarten befindet (doch nicht mehr als zu einem. Viertel des Bestandes).

In Lärchenkulturen ist schon zeitig mit dem Lichtungshieb anzufangen, da die dürren Exemplare die Verbreitung des Lärchenkrebses begünstigen.

Im Vergleich zu der europäischen Lärche (Larix decidua) und Sukatschows Lärche (L. sukaczevii) sind die japanische Lärche (L. leptolepis), sowie die kurilische (L. kurilensis) dem Lärchenkrebs gegenüber widerstandsfähiger. Im Versuchsforstwirtschaitsbetrieb der Estnischen Landwirtschaftlichen Akademie blieben kleinere Kulturen dieser Arten vom Lärchenkrebs völlig unversehrt.

Institut für Zoologie und Botanik der Akademie der Wissenschaften der Estnischen SSR
Eingegangen am 6. März 1959 